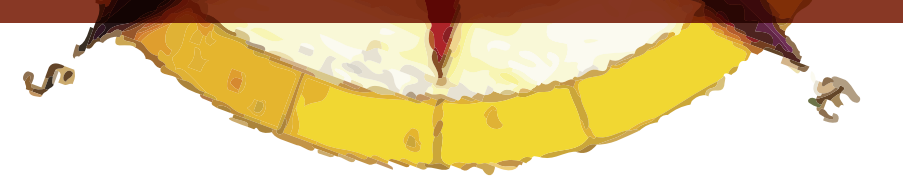

\title{
PRÁTICAS CURRICULARES DE GEOGRAFIA EM ESCOLAS PÚBLICAS DO RIO DE JANEIRO: A PERSPECTIVA DAS PROFESSORAS: UM ESTUDO DOS DIÁRIOS DE CLASSE
}

\author{
Gabriel B. C. Pedro ${ }^{1}$
}

\section{RESUMO}

Este trabalho busca investigar o cotidiano escolar através da perspectiva de professoras de séries iniciais no ensino de Geografia, entendendo este cotidiano como uma realidade complexa e dinâmica. Esta investigação se deu pela análise dos diários de classe destas professoras, procurando os principais problemas com os quais elas se deparam ao ensinar Geografia para as séries iniciais, os chamados dilemas (Zabalza, 1994). Escolheu-se trabalhar com os dilemas porque, segundo Straforini (2008), existem muitas dificuldades no ato de ensinar Geografia para as séries iniciais do Ensino Fundamental no atual contexto de mundo altamente complexo e multi-escalar. Os diários nos propiciam um olhar privilegiado tanto sobre as práticas pessoais destes professores quanto sobre os seus pensamentos, crenças e convicções que por sua vez fomentaram, construíram/re-construíram e justificaram as suas práticas.

Palavras Chave: Cotidiano escolar, ensino da geografía, séries iniciais, diarios de classes.

\section{RESUMEN}

Este trabajo busca investigar el cotidiano escolar a través de la perspectiva de las profesoras de los años iniciales de la enseñanza de la Geografía, entendiendo este cotidiano como una realidad compleja y dinámica. Esta investigación se dio por el análisis del libro de clases de estas profesoras, observando los principales problemas con los cuales ellas se deparan al enseñar la Geografía para los años iniciales, los llamados dilemas (Zabalza, 1994). Se escogió trabajar con los dilemas porque, según Straforini (2008), existen muchas dificultades en el acto de enseñar Geografía para los años iniciales de Enseñanza Básica en el actual contexto de mundo altamente complejo y multiescalar. Los libros nos propician un mirar privilegiado tanto sobre las prácticas personales de estos profesores cuanto sobre sus pensamientos, creencias y convicciones que por su vez fomentan, construyen/ re-construyen y justifican sus prácticas.

$1 \quad$ Estudiante de la Universidad Federal de Río de Janeiro 
Palabras Clave: Cotidiano escolar, enseñanza de la geografía, años iniciales, libro de clases.

\begin{abstract}
This work is focus in the school quotidian research, through the women teacher perspective in early years of Geography teaching, understanding this quotidian like a complex and dynamic reality. This research was possible by the school books analysis of these women teachers, watching the main problems they confront teaching Geography in the early years, the called dilemmas (Zabalza, 1994). The idea to explore the dilemmas is explained, quoting Straforini (2008), who thinks there are many difficulties in the Geography teaching in the early years in basic education in the highly complex and multi scale world. The books give us a privileged capacity to look in personal practices of these teachers about their thoughts, believes and convictions, that encourage, build/rebuild and justify their practices.
\end{abstract}

Keywords: School quotidian, geography teaching, early years, class books.

\title{
INTRODUÇÃO
}

Este trabalho está inserido dentro de um contexto mais amplo da linha de pesquisa sobre práticas pedagógicas e curriculares no ensino de Geografia, pertencente ao Ateliê de Pesquisas e Prática em Ensino de Geografia (APEGEO), coordenado pelo Prof. Dr. Rafael Straforini. O discurso orientador das atividades do grupo segue um posicionamento científico/político/social do pensamento pós-crítico dentro do âmbito das pesquisas em educação, onde o ensino é entendido como um processo complexo e dinâmico, e tanto o conhecimento quanto o processo de ensiná-lo/construí-lo são sinônimos de poder e emancipação.

Este trabalho busca investigar as particularidades do cotidiano escolar através da perspectiva do professor, mais especificamente àquelas que dizem respeito ao ensino de Geografia. Aquilo que procuramos pesquisar inclui, dentre outras coisas, o que os professores pensam a respeito das qualidades - sejam estas positivas ou negativas - de sua sala de aula, dos seus alunos e de sua própria prática. Entretanto, é importante salientar que, ao declararmos como importante à nossa pesquisa as perspectivas dos professores e as suas opiniões sobre questões do cotidiano escolar, estamos nos interessando não mais apenas por questões práticas e eventos concretos da sala de aula, mas também - e agora, principalmente - pelos significados que os professores atribuem a estes, e para sua atuação profissional, como um todo.

A "geograficidade" de nossa linha de pesquisa, ou seja, o caráter geográfico que distingue este trabalho de outros trabalhos de caráter exclusivamente pedagógicos, reside nas especificidades presentes no ensino da Geografia enquanto disciplina escolar, ou seja, nas diferentes práticas curriculares que se manifestam no cotidiano escolar no decorrer do processo de ensino/aprendizado geográfico, e nos diferentes recortes epistemológicos produzidos pela/para a Geografia escolar durante este processo. O trabalho aqui apresentado irá buscar investigar as especificidades do ensino escolar da Geografia a partir da perspectiva das professoras das séries iniciais. Entretanto, sobre qual Geografia exatamente estamos falando? 


\section{DESENVOLVIMENTO}

Milton Santos (2002) afirma, em seu livro "Por uma outra globalização", que a realidade em que vivemos hoje constitui um todo sistêmico, desigual e combinado que se faz presente em todo o mundo, conseqüência de um processo histórico essencialmente capitalista e feito possível graças aos imperativos técnicos, científicos e informacionais de nossa época. Isto significa dizer que as diferentes regioes do mundo se encontram cada vez mais interconectadas e interdependentes, e que este processo foi viabilizado pelos avanços tecnológicos que surgiram - e surgem - no atual esquema técnico-científico mundial. Entretanto, é importante fazer duas ressalvas: o processo que propicia a crescente interconectividade do mundo, a globalização, diferente do que sua nomeclatura sugere, é um processo altamente desigual justamente por estar acontecendo em um mundo altamente desigual, onde ambos estao sujeitos à dinâmica do capitalismo. Sendo assim, a segunda ressalva que é preciso ser feita é que, embora a globalização esteja sim ocorrendo a um nível mundial, ela nao está ocorrendo com a mesma intensidade em todos os lugares e regioes e, portanto, apresenta impactos diferenciados em diferentes localidades do globo.

É importante destacar aqui que concordamos com essa leitura, não enquanto verdade absoluta, mas como um princípio para reflexões acerca de fenômenos espaciais no âmbito da educação. Tomando esta visão de mundo como ponto de partida, e levando-a em conta no processo de ensino/ aprendizagem de Geografia nas escolas, é importante nos questionarmos: "Como ensinar o espaço geográfico como uma todo sistêmico, onde as dimensões escalares - local, regional, nacional e global - se sobrepõem e se complementam, dentro de uma estrutura escolar que preza a compartimentação do conhecimento?"

Para Straforini (2008), esta compartimentação do conhecimento em disciplinas e conteúdos estanques nas escolas pode provocar nos alunos uma dificuldade de traçar paralelos entre a Geografia ensinada e a realidade à qual esta diz respeito, principalmente nas séries iniciais. Justamente por este motivo é que neste trabalho nos interessamos pelo ensino da Geografia nas séries iniciais, e as diferentes formas que as suas professoras encontram para trabalhar a disciplina em sala de aula, ou seja, as suas práticas curriculares.

As práticas curriculares às quais nos referimos são práticas relacionadas não apenas à noção de currículo enquanto documento oficial, mas principalmente enquanto algo vivido, praticado e produzido cotidianamente pelos diversos sujeitos do processo educacional. Com isso em mente, é possível afirmar que a construção de um currículo é altamente múltipla, conflituosa, e por vezes até contraditória; porém, mais do que todas essas coisas, ele é processual. É ao falarmos deste currículo que a perspectiva das professoras, enquanto participantes do processo de construção do currículo, se faz relevante para esta investigação.

Este trabalho tem a sua temática situada no âmbito da educação, onde a nossa compreensão está em sintonia com a de Zabalza (1994) de que o ensino, por sua natureza, integra o componente da ação com o da mente, ou seja, o que aquela ação significa para quem participa dela. A integralidade pensamento/ação é muito relevante, pois ela situa dentro das esferas do investigável, e do importante de investigar, os pensamentos dos professores e dos seus alunos, ou seja, o lado subjetivo do ensino. Além deste pressuposto teórico, concordamos com a concepção de aula enquanto realidade social e dinâmica, e com a do professor enquanto profissional que delibera e reflete sobre a sua própria atuação profissional. 
Segundo Ghedin e Franco (2008) existem três tipos básicos de modelos que interpretam de maneiras diferentes a relação sujeito-objeto: o modelo objetivista, que se associa à metodologia quantitativa, e os modelos subjetivistas e dialéticos, que se associam à metodologia qualitativa. O modelo objetivista, segundo os autores, interpreta o mundo de uma maneira mais estanque, sendo propenso a formulação de leis imutáveis, e fazendo clara cisão entre objeto e os valores e significados a ele atribuídos. Os modelos subjetivistas e/ou dialéticos, por outro lado, já interpretam o mundo de uma maneira menos rígida, levando muito mais em conta os significados atribuídos às coisas do que as coisas em si; porém, apenas o modelo dialético vê o conjunto de significações atribuídos ao mundo pela sociedade como resultante de um processo histórico, e, desta maneira, como um processo sempre em movimento e dinâmico. A metodologia de nossa pesquisa é, então, qualitativa, e o nosso modelo metodológico, dialético, na medida em que os pressupostos teóricos associados a estas visões metodológicas se encontram mais alinhados com a nossa visão de mundo, dinâmico e carregada de significados, do que o modelo subjetivista, ou o modelo objetivista/quantitativo.

Para melhor compreender a perspectiva das professoras sobre o ensino de Geografia, nós escolhemos trabalhar com os diários de aula como ferramenta de investigação. Esta escolha foi feita baseada principalmente no próprio Zabalza, que aponta a relevância dos diários de aula dentro das pesquisas qualitativas em educação. Para ele, o valor dos diários reside na proximidade cronológica entre eventos e registros, a possibilidade de uma análise longitudinal da prática das professoras, e principalmente no caráter reflexivo de seu texto. É por conta deste caráter reflexivo dos diários que Zabalza acredita ser possível não apenas conhecer a prática cotidiana das professoras, mas também as professoras em si; através dos diários de aula, obter acesso àquilo que Zabalza apoiado em Bauch (1984) chama de "crenças", e que apoiado em Janesick (1978) chama de "perspectivas": estruturas mentais mais ou menos definidas, baseadas em valores, objetivos, interesses, etc., que são altamente dinâmicas e, às vezes, contraditórias, e que vão, por fim, dar direção às práticas docentes das professoras.

Ainda tomando por orientação o trabalho de Zabalza, a análise dos conteúdos presentes nos diários de aula concentrou-se em torno do conceito de "dilema", situações-problema do cotidiano aonde as professoras são obrigadas a problematizar suas práticas docentes, conscientemente ou não, desenvolvendo assim a sua própria forma de processar informações e de tomar decisões. A escolha pela utilização dos "dilemas" é justificável porque neles está implícito o caráter de contingência da educação, e nos possibilita romper com a simplicidade da lógica pensamento-ação na prática das professoras, e a enxergar a relação dialética entre o desejável e aquilo que é possível em sala de aula.

Quanto à coleta dos dados, duas ressalvas tiveram que ser abordadas: a amostragem dos dados, e os cuidados metodológicos a serem tomados durante a sua coleta. Zabalza se apoia fortemente em Allport (1942), a respeito da amostragem dos dados, e afirma que a necessidade das pesquisas quantitativas da representatividade dos dados não se faz obrigatoriamente presente nas pesquisas com documentos pessoais, na medida em que estas, por possuírem um caráter mais ideográfico, estão mais interessadas nas singularidades do que na busca por regras. Não há obrigatoriamente intenção de generalizações, e se elas existem, são apenas generalizações intermediárias, ou seja, estender os resultados da pesquisa apenas a grupos próximos e homogêneos ao objeto de investigação.

Quanto aos cuidados metodológicos a serem tomados, Zabalza afirma que o principal perigo da pesquisa com documentos pessoais é a conceitualização arbitrária ou tendenciosa de um sistema de coleta de dados, ou seja, quando o pesquisador procura avalizar uma teoria previamente elabo- 
rada, tornando tendencioso o seu olhar sobre os seus dados. Para evitar esse perigo, "o procedimento legítimo de conceitualização de um material só pode resultar de uma adequada e dialética interação entre o que os fatos [...] são em si mesmos, e o contributo da teoria" (p.90), sem esquecer que não existe um critério geral de análise que garanta uma única forma de interpretar um texto, sendo, portanto, adequado considerar que a interpretação feita em cima de qualquer texto será apenas uma das várias possíveis.

Agora, o trabalho em si. Foram transcritos os diários dos anos de 2004 a 2009 de seis professoras, ao todo, do quadro de funcionários permanente de escola pública da zona sul do Rio de Janeiro. Foram transcritos os diários dos anos de 2004 a 2009 de seis professoras, ao todo, do quadro de funcionários permanente da Escola Municipal Alberto Barth. Os diários da escola estavam divididos em duas partes principais: a ação pedagógica, e as anotações diárias. O segmento de ação pedagógica, por sua vez, se dividiu em outras duas - planejamento pedagógico (atividades diagnósticas, e propostas de trabalho) e replanejamento periódico (necessidades da turma, e revisões do planejamento pedagógico) - e foi transcrito na integra para os documentos digitais. No segmento das anotações diárias eram descritas as principais atividades e conteúdos que eram trabalhadas em sala de aula, porém apenas foi transcrito aquilo que dizia respeito ao ensino em Geografia, especificamente.

Após a conclusão da transcrição dos diários de aula, a análise do material teve início. Com esse intuito, lançamos mão de uma estrutura analítica organizada por Zabalza em três partes: uma primeira leitura genérica de penetração global no campo, uma segunda leitura de identificação dos tópicos e situações onde os dilemas dos professores surgiam, e finalmente uma terceira leitura onde são estabelecidas relações entre cada um dos componentes dos dilemas e cada uma das fases de sua evolução. Por se tratar de um esforço investigativo específico em ensino de Geografia, o sistema de análise dos foi mais ou menos conformado para atender às demandas deste objetivo.

A primeira leitura do material colhido serviu para introduzir ao grupo de pesquisa aquela realidade docente específica: a escola em si, suas professoras e os elementos do cotidiano que elas consideram dignos de nota ou relevantes. No que tange ao ensino da Geografia, especificamente, procurou-se identificar a existência - ou não - de uma preocupação por parte das professoras de incluir a disciplina geográfica em seus planejamentos, e de efetivamente refletir a respeito da melhor maneira de trabalhar os conceitos espaciais em sala de aula com seus alunos do Ensino Fundamental. Esta primeira leitura aponta para dois pontos dignos de nota. Primeiramente, fica evidente a predileção pelas disciplinas Português e Matemática por parte das professoras, e em detrimento das outras disciplinas, tanto durante a seção "ação pedagógica" quanto na seção "ações diárias". Esta predileçao fica clara ao observar o Quadro $\mathbf{N}^{\mathbf{0}} \mathbf{1}$.

Em segundo lugar, mesmo naqueles poucos conteúdos geográficos que surgem durante os diários de classes das professoras, não parece ter havido em nenhum momento durante o processo de diagnóstico da aprendizagem uma atenção séria ao domínio de seus alunos quanto a conceitos e noções espaciais, como é visto no Quadro $\mathbf{N}^{\circ} 2$.

A segunda leitura do material colhido a partir dos diários de classe serviu para explorarmos um pouco mais o que as professoras com quem trabalhamos chamam de 'Geografia'. Partindo do pressuposto que a disciplina geográfica é trabalhada em sala de aula por essas professoras com o mínimo de reflexão e de planejamento possíveis, pressuposto este obtido através da primeira leitura, é interessante entender a maneira como estas professoras delimitam em suas práticas o que é e o que não é considerado Geografia. Na verdade é possível perceber nesta necessidade cotidiana de 
delimitação, os dilemas das professoras em relação ao ensino de Geografia: afinal de contas, o que é 'Geografia' para elas? Aonde é feita a delimitação destes conteúdos? ela acontece em um momento pré-ativo, durante as aulas em si, ou em um momento pós-ativo?

\begin{tabular}{|c|c|}
\hline \multicolumn{2}{|c|}{ Professora A } \\
\hline Português/Matemática & Geografia \\
\hline $\begin{array}{l}\text { 2006: } \\
\text { 'Acão pedagógica' } \\
\text { Propiciar leituras de poesias histórias coletiva e } \\
\text { individualmente - para avaliá-los. } \\
\text { Colocar pequenos textos no (com cerca de } 3 \text { pará- } \\
\text { grafos) propondo que registrem no caderno obedecen- } \\
\text { do as mesmas estruturas. } \\
\text { Apresentar o "Meu primeiro dicionário Larousse" } \\
\text { epedir que consultemos individualmente os nossos. } \\
\text { Propor ditados de frases e corrigi-las. } \\
\text { Rever quantidade, hora, soma, subtração, e na } 2 a \\
\text { quinzena de fevereiro, aplicar avaliaçóes. } \\
\text { Deverei exercitar as operações matemáticas com } \\
\text { uso de material concreto. Por isso, penso em trazer os } \\
\text { ábacos para os alunos. } \\
\text { Para desenvolver a interpretação e a redação darei } \\
\text { notoriedade a literatura quase que diariamente. Já se- } \\
\text { lecionei, para isso, dois livros extra-classe: Histórias } \\
\text { Fabulosas de Esopo e La Fontaine; e Lendas do Brasil } \\
\text { da Editora Girassol. }\end{array}$ & $\begin{array}{l}\text { 2006: } \\
\text { 'Acãa Pedagógica', } \\
\text { Estes livros vão me apoiar também em estudos sociais } \\
\text { e ciências, pois suas histórias se baseiam em animais, } \\
\text { florestas e natureza brasileira. No mês da Mulher va- } \\
\text { mos conhecer os Contos de Sherazade. }\end{array}$ \\
\hline $\begin{array}{l}\text { 2004: } \\
\text { ‘Acãa Pedagógica' } \\
\text { PORTUGUÊS: Trabalho na leitura de textos; criação } \\
\text { de textos coletivos e individuais; interpretação de pa- } \\
\text { lavras, frases, textos, textos matemáticos; } \text { empréstimos } \\
\text { de livros e debates sobre eles; letras de músicas; dra- } \\
\text { matização e brincadeiras. }\end{array}$ & 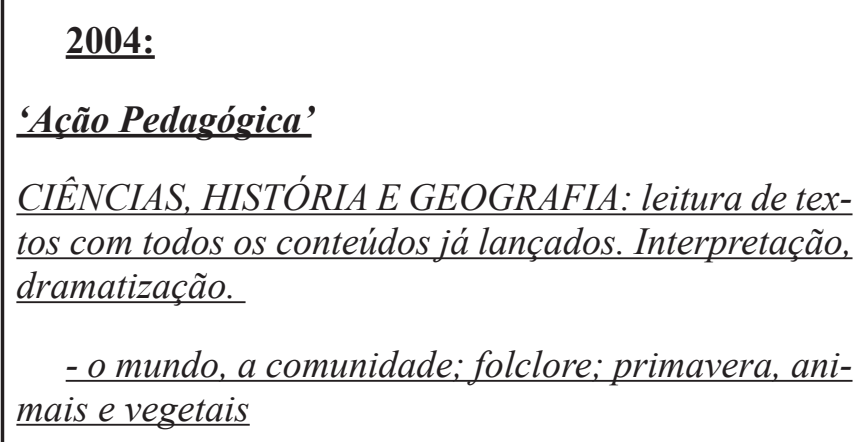 \\
\hline
\end{tabular}




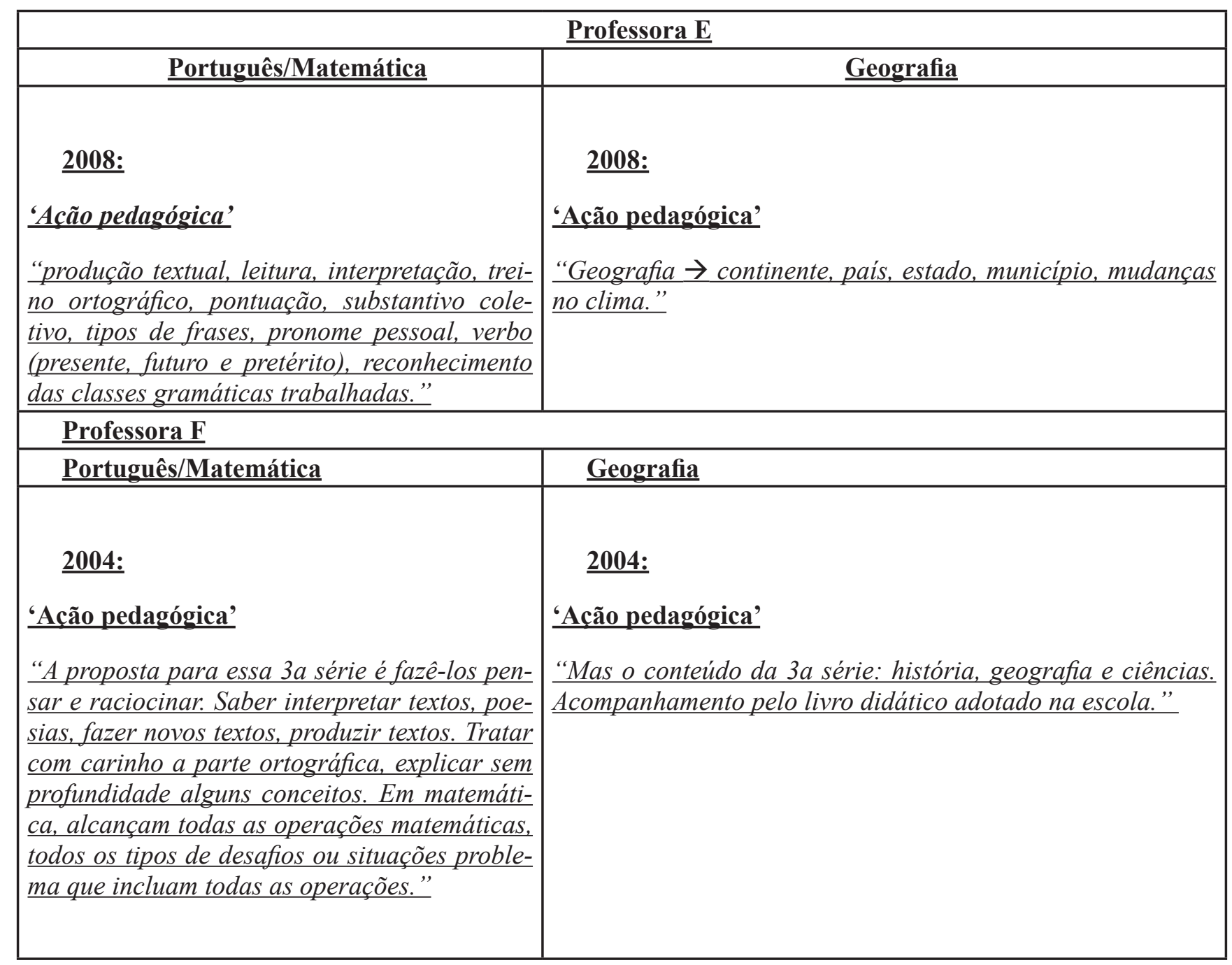

Quadro No2

A segunda leitura do material levantado dos diários de classe aponta para a formação de três classes que mais ou menos abarcam os conteúdos trabalhados sob o signo da Geografia nas salas de aulas das professoras com quem trabalhamos: i) o cumprimento do conteúdo programático; ii) educação ambiental; e iii) datas comemorativas. O cumprimento do conteúdo programático, como o próprio nome já diz, são aqueles conteúdos que se encontram na pauta das professoras enquanto Geografia apenas pelo fato de se encontrar previsto no programa curricular. Esta categoria está ligada intimamente ao uso dos livros didáticos em sala de aula, por parte das professoras, para orientar suas práticas cotidianas em relação ao ensino de Geografia. A título de exemplo, se pode observar esta prática no Quadro No3.

A educação ambiental é um tema que tem estado bastante em evidência, tanto na mídia quanto em pautas políticas e educacionais. Não coincidentemente, é também um tema que surge com bastante recorrência nos diários de classe, atrelado a uma série de disciplinas diferentes. Desde que os Parâmetros Curriculares Nacionais foram publicados em 1997 que o Meio Ambiente é - ou deveria ser - pensado enquanto um tema transversal, ou seja, de domínio universal e que transpassa e per- 
tence a todas as disciplinas escolares. Entretanto, é evidente que existem algumas disciplinas que se apropriaram com maior sucesso da temática ambiental e que, hoje em dia, possuem diferentes facetas desta atreladas aos seus conteúdos. As Ciências são um bom exemplo desta apropriação; a Geografia é outro. Após a segunda leitura dos diários de classes das professoras com quem trabalhamos, percebeu-se um padrão de conteúdos relacionados ao ensino do Meio Ambiente, mas que por conta disso perderam seu vínculo direto com esta ou aquela disciplina escolar específica, fazendo com que as professoras muitas vezes atribuam o mesmo conteúdo relacionado à educação ambiental a diferentes disciplinas escolares em diferentes anos letivos, como é perceptível no Quadro $\mathbf{N}^{\mathbf{0}} 4$.

Por último, nós temos as comemorações de datas especiais ligadas quase que exclusivamente, também, às ciências humanas - exceção feita, dentre pouquíssimas outras, ao Dia Mundial do Meio Ambiente (05 de junho), que também se relaciona bastante com a disciplina Ciências. A relação feita entre a Geografia escolar e as datas comemorativas nas práticas docentes das professoras pode ser resultado de uma ausência de um planejamento e de uma intenção curricular, e passa assim a se materializar em práticas marcadas pela instantaneidade dos contextos do cotidiano escolar. $\mathrm{O}$ forte relacionamento entre a disciplina geográfica e as datas comemorativas fica clara no Quadro No5.

Durante a terceira leitura de estabelecimento de relações entre cada um dos componentes dos dilemas, duas questões surgiram como pontos de interesse: a primeira foi o aparente descaso com o planejamento da Geografia escolar, e como este pode ser um produto, de acordo com Straforini (2008), Torres (1996) e Gonçalves (1999), de uma tendência cada vez mais vigente da atuação dos grandes órgãos supranacionais de financiamento econômico, como o Banco Mundial por exemplo, que rendem as políticas educacionais nacionais às suas demandas, sob o incentivo de maiores linhas de crédito e melhores taxas de juros para os Estados com os índices educacionais mais elevados. Para Barreto e Leher (2008), o próprio Banco Mundial se posiciona como quem sabe o que é melhor para o mundo, e se utiliza de seu poder político-econômico para ajustá-lo a essa formatação. Este posicionamento da agência fica claro em sua página virtual, onde a mesma disponibiliza o perfil educacional dos países com ela envolvidos, e uma Estratégia Educacional para os próximos 10 anos.

A relação entre as nossas políticas públicas nacionais e os grandes órgãos supranacionais de financiamento econômico se manifesta materialmente nos nossos cotidianos escolares na forma das avaliações integradas em nível nacional, como o Prova Brasil, onde as únicas disciplinas avaliadas são Português e Matemática. O índice decorrente - o IDEB - tem como objetivos padronizar a educação escolar brasileira e quantificar a qualidade do seu ensino, mercantilizá-la para que, desta maneira, distribuam-se mais recursos para as escolas que obtiverem as melhores posições no ranking de "qualidade". Estas avaliações nacionais valorizam justamente as disciplinas que os órgãos supranacionais de financiamento utilizam como critérios de desenvolvimento educacional, e parece óbvio que as escolas públicas a procura de mais recursos irão se conformar com as diretrizes estabelecidas pelos detentores do capital.

A segunda questão que surgiu foi a possibilidade de perceber a configuração de uma confusão entre os limites da disciplina geográfica, com os limites da História e Ciências, confusão esta que é compreensível quando percebemos que no Ensino Fundamental - no ensino básico como um todo, mas principalmente no Fundamental - existe uma proximidade epistemológica muito grande entre estas disciplinas. A relação feita entre a Geografia escolar e as datas comemorativas nas práticas docentes das professoras pode ser resultado de uma ausência de um planejamento e de uma intenção curricular, e passa assim a se materializar em práticas marcadas pela instantaneidade dos contextos 
do cotidiano escolar.

\begin{tabular}{|c|c|c|}
\hline Professora $\mathrm{C}$ & Professora $\mathrm{E}$ & Professora $F$ \\
\hline 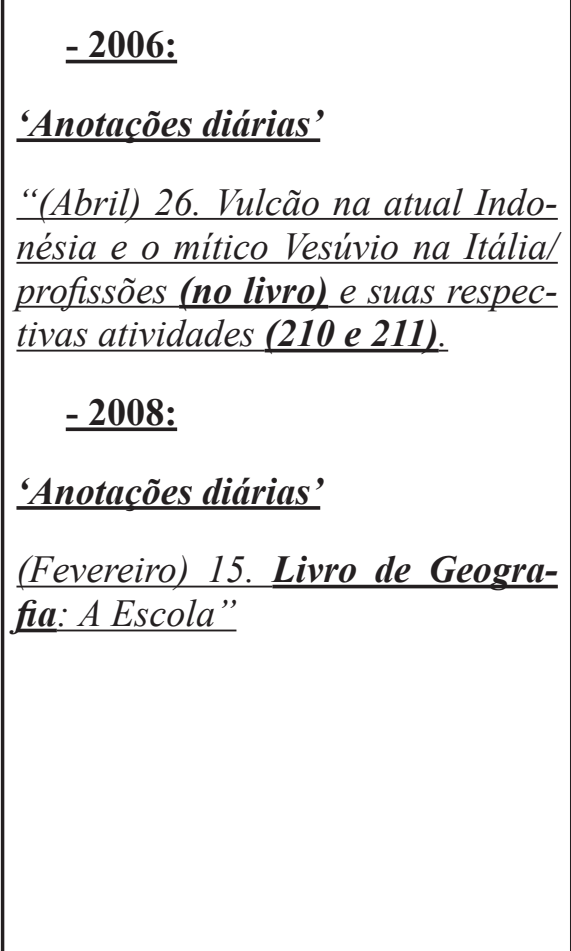 & $\begin{array}{l}\quad \text {-2008: } \\
\text { 'Anotacões diárias" } \\
\text { “(Abril) 03. Livro de História p. } 106 \\
\underline{\text { 107. }} \\
\text { 11. Livro de Geografia p. } 96 \text { e } 97 . \\
\text { 17. Livro de História p. } 108 \text { e } 109 . \\
\text { 18. Livro de Geografia p. } 98 \text { e } 99 . \\
\text { 24. Livro de História p. } 110 \text { e } 111 .\end{array}$ & $\begin{array}{l}\text { 13. Geografia (pecuária-livro) } \\
\text { 28. Geografia: livro - atividades } \\
\text { agropecuárias, extrativismo mine- } \\
\underline{\text { ral. }} \\
\quad \text { 2008: } \\
\frac{\text { Anotacões diárias' }}{\text { “(Julho) 11. Geografia: livro, p. }} \\
\underline{\mathbf{5 1 / 6 1}} \\
\text { 18. Geografia: livro, p. 66/75”, }\end{array}$ \\
\hline
\end{tabular}

\section{Quadro $\mathrm{N}^{\circ} 3$}

\begin{tabular}{|c|c|}
\hline \multicolumn{2}{|c|}{ Professora A } \\
\hline Ciências & Geografia \\
\hline 2006: & 2007: \\
\hline 'Acõos pedagógicas’' & 'Anotacõos diárias’ \\
\hline "CIÊNCIAS: lixo, reciclagem, violência, saúde" & "(Nov.) Geografia: problemas ambientais" \\
\hline \multicolumn{2}{|l|}{ Professora F } \\
\hline Ciências & Geografia \\
\hline 2004: & 2008: \\
\hline 'Anotações diárias’' & ‘Anotacões diárias’ \\
\hline "(Outubro) Ciências: fontes poluidoras da água" & "(Abril) 07. Teste de geografia - desequilibrios provo- \\
\hline 'Anotações diárias’' & cados pelo homem. \\
\hline $\begin{array}{l}\text { "(Abril) 08. Ciências: [...] trabalho sobre coleta sele- } \\
\text { tiva e lixo." }\end{array}$ & \\
\hline
\end{tabular}




\begin{tabular}{|c|c|}
\hline Professora D & Professora F \\
\hline 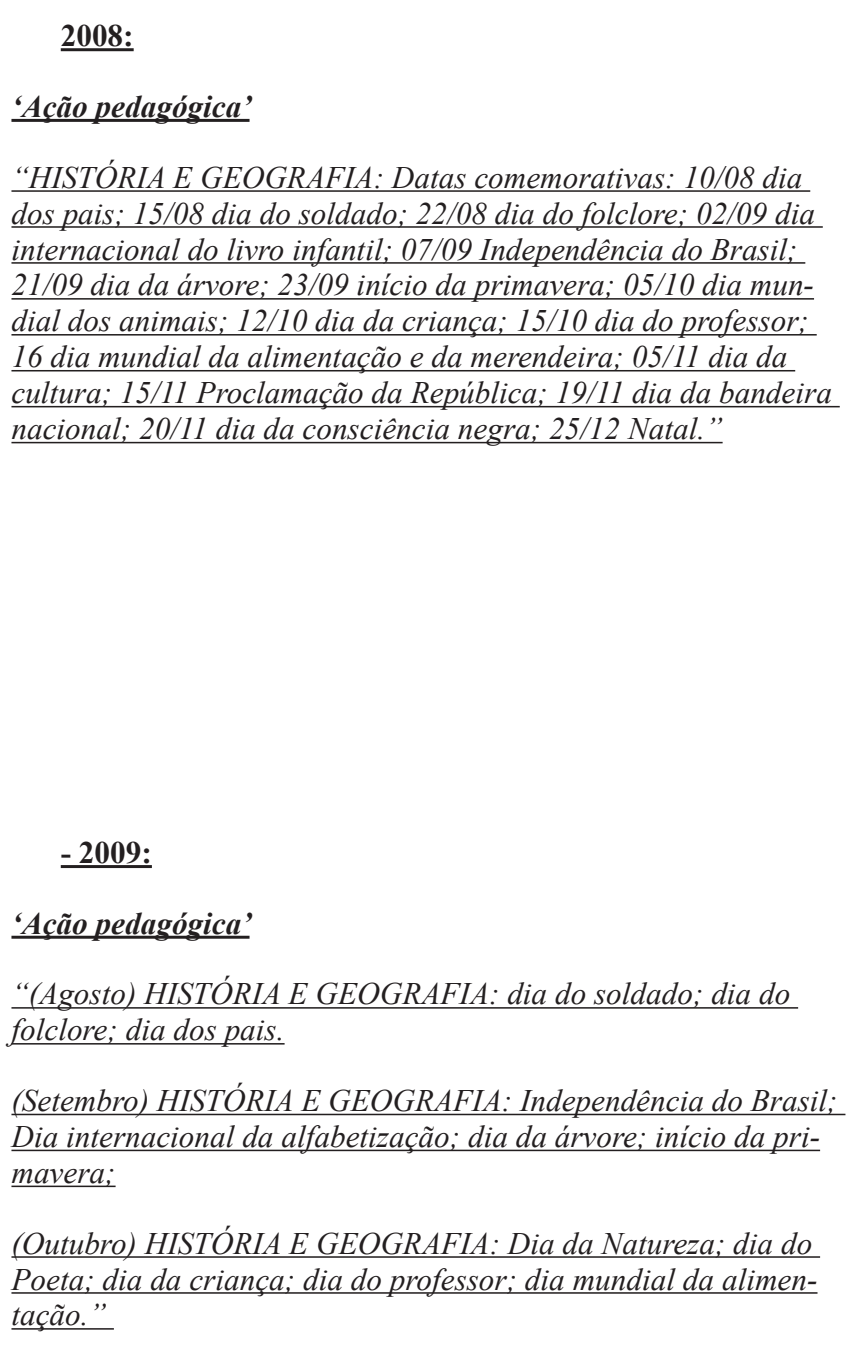 & 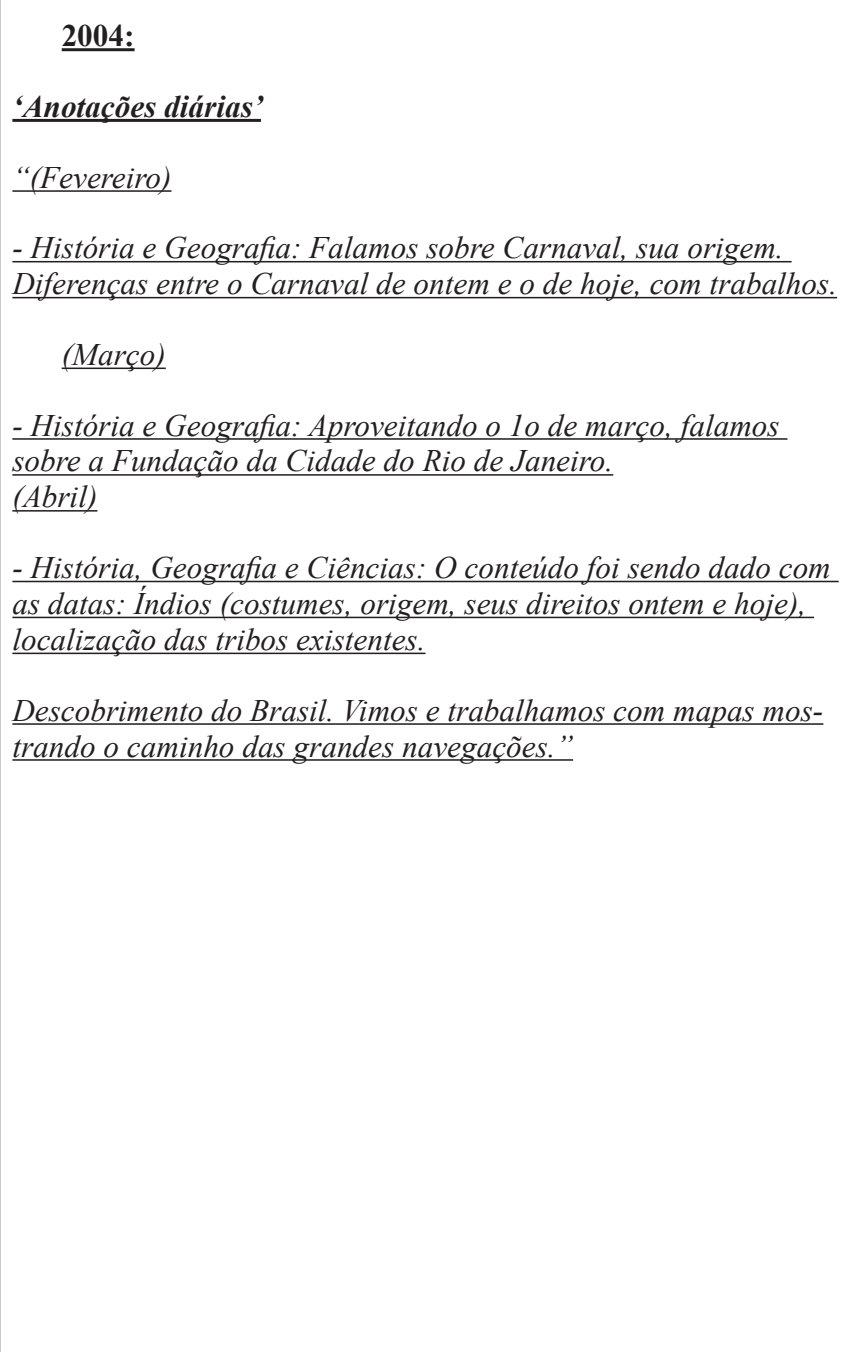 \\
\hline
\end{tabular}

Quadro No5

A partir das teorias curriculares pós-críticas vêm o entendimento de que o processo de ensinar é um jogo de poderes, em essência, e o saber por ele construído é sinônimo de poder para quem participa do processo; por sua vez, ensino e aprendizagem são compreendidos enquanto ações emancipatórias. Tanto o ensino em si, quanto a pesquisa sobre o ensino compartilham desta característica e do compromisso conseqüente com um projeto de transformação da sociedade pela educação.

Mais do que apenas uma contribuição significativa para o acervo brasileiro limitado de trabalhos científicos sobre diários de aula, este trabalho teve - e tem - como um de seus propósitos principais e como uma de suas conseqüências esperadas, a transformação, se não ainda da sociedade, mas daqueles envolvidos no processo de pesquisa.

A análise preliminar dessas narrativas nos permite articular a triangulação currículo, cotidiano 
escolar e Registros de Classe. Passados quatorze anos da publicação dos PCN de Geografia para esse nível de escolarização, a Geografia continua ocupando espaço secundário no planejamento e na preocupação dos professores. Em nenhum momento foi encontrada uma menção se quer a conceitos espaciais nos escritos referentes ao diagnóstico da classe. Se é que isso pode nos confortar, esse não é um mal apenas da Geografia, mas também de outros componentes curriculares, como a História, Artes e Ciências.

Quanto aos conteúdos expressos no quadro relativo ao planejamento, identificamos aquilo que Gvirtz e Larrondo (2008, p.37) chamou de continuidade dos conteúdos relativos ao currículo anterior a uma dada reforma curricular. Mas em se tratando de geografia escolar, o conteúdo exposto se quer se encaixa ao currículo oficial anterior aos PCN e da MultiEducação. Ou seja, nesse nível de escolarização o estranhamento entre aquilo que se produz na academia enquanto critica ao currículo prescritivo e ao currículo praticado é elevada à máxima potência. Mais de $90 \%$ dos conteúdos designados como geográficos e históricos continua sendo as datas comemorativas. Há data comemorativa para tudo! Mas isso não significa que no ano seguinte a professora repetirá a comemoração dessa mesma data. Acreditamos que isso ocorre porque não sendo considerado como um componente curricular significativo, o currículo de geografia deixa de ser um produto oriundo de um planejamento e de uma intenção curricular e se materializa em práticas marcadas pela instantaneidade dos contextos do cotidiano escolar: um sobejo de tempo no final do turno de aula que deve ser ocupado com algo para distrair, uma atividade mimiografada para descansar os alunos dos conteúdos exaustivos de matemática e língua portuguesa, esses sim presentes enquanto algo planejado, re-planejado, reflexivo e intencionalizado. Estamos chamando essa prática curricular de geografia mimiográfica.

Sobre essa arquitetura do tempo escolar (Viñao, 2008, p.22), os registros de classe não só mostram que o tempo escolar é um tempo social, uma construção cultural e acadêmica, mas, ao mesmo tempo, desvela a vida cotidiana, a intra-história das instituições educativas e, sobretudo, reais do currículo praticando.

Outra narrativa expressa nos registros é a frivolidade dos conteúdos relativos à natureza: pois ora aparecem como conteúdos de ciências, ora de Geografia e ora como de educação ambiental.

O maior trunfo dos trabalhos com diários de aula reside na expectativa de que os professores descubram nestes diários uma ferramenta poderosa de reflexão, re-construção e re-significação das suas práticas profissionais e visões de mundo, tornando-as mais críticas. E, com alguma sorte - se formos capazes - também reside na possibilidade de que os pesquisadores, ao irem para fora dos muros da faculdade e para dentro do cotidiano escolar, consigam tanto estes quanto os professores se beneficiarem mutuamente desta amplamente negligenciada, mas maravilhosamente profícua relação entre academia e escola.

Com esta etapa da pesquisa concluída, se inicia o processo de dar continuidade a esta investigaçao. Os próximos passos previstos para o ano de 2012 sao: Formular um questionário semi-estruturado a ser aplicado junto às professoras; adentrar no cotidiano escolar, para observá-lo em toda sua complexidade, sem deixar de levar em conta a perspectiva das professoras; e investigar mais a fundo a relação entre a escala das políticas públicas de formação do currículo, e a escala das práticas individuais das professoras, atentando sempre aos cuidados metodológicos necessários para trabalhar com dois escopos tão diferenciados. 


\section{BIBLIOGRAFIA}

Ghedin, E.; Franco, M. (2008). Questões de método na construção da pesquisa em educação. São Paulo: Cortez Editora.

Gvirtz, S; Larrondo, M. (2008). Os cadernos de classe como fonte primária de pesquisa: alcances e limites teóricos e metodológicos para a sua abordagem. In: MIGNOT, Ana Chrystina Venâncio (org.). Cadernos à vista: escola, memória e cultura escrita. Rio de Janeiro: EDUERJ.

Oliveira, Inês Barbosa de. (2005). Currículos Praticados: entre a regulação e a emancipação. Rio de Janeiro: DP\&A.

Santos, M. (2000). Por uma outra globalização: do pensamento único à consciência universal. Rio de Janeiro: Record.

Silva, T. T. da. (2007). Documentos de identidade: uma introdução às teorias do currículo. Belo Horizonte: Autêntica.

Straforini, R. (2008). Ensinar geografia: o desafio da totalidade-mundo nas séries iniciais. São Paulo: Annablume.

Viñao, A. (2008). Os cadernos escolares como fonte histórica: aspectos metodológicos e historiográficos. In: MIGNOT, Ana Christina Venâncio (org.). Cadernos à vista: escola, memória e cultura escrita. Rio de Janeiro: EDUERJ.

Zabalza, M. (1994). Diários de Aula: contributo para o estudo dos dilemas práticos dos professores. Porto: Porto Editora. 